\title{
An unusual variant of the hypothenar hammer syndrome
}

\author{
D MOSQUERA, M GOLDMAN
}

From the Department of Surgery, East Birmingham Hospital, Bordesley Green, Birmingham B9 5ST, UK

The hypothenar hammer syndrome (HHS) is an occupational disorder of the arterial vessels in the hand. ${ }^{1-5}$ We present two patients with an unusual variant of this condition which is difficult to differentiate from industrial white finger.

\section{Case 1}

A 48 year old man presented with a seven month history of coldness, pain, numbness, and poor healing in the middle, ring, and little fingers of his right hand. These symptoms were exacerbated by exposure to cold and a small ulcer had recently developed at the tip of his right middle finger. He was a manual worker with a 20 year history of using his right hand as a hammer. He was not diabetic but smoked $\mathbf{4 0}$ cigarettes a day. He was not taking medication when seen but for one year previously had been taking propranolol and carbimazole for thyrotoxicosis.

Examination showed that the affected fingers were colder than the corresponding fingers on the left hand and a small ulcer was present at the tip of the blanched right middle finger. Results of the remainder of the cardiovascular and general examination were normal, in particular no bruits were heard. All routine screening investigations for arm ischaemia were normal and in view of the presence of undiagnosed, unilateral, digital ischaemia, an arch aortogram was performed. This showed a local aneurysmal dilatation of the ulnar artery in the palm, with poor filling of the digital vessels especially those to the middle and ring fingers (figure). In view of the poor blood supply to the fingers and the presence of an ulcer it was decided to perform a cervical sympathectomy. After operation, the ulcer on the middle finger healed and at seven years follow up the patient is well with no symptoms from his right hand but with a small puckered scar at the tip of his right middle finger.

\section{Case 2}

A 50 year old man presented after six weeks with a history of sudden onset of pain, tingling, coldness, and

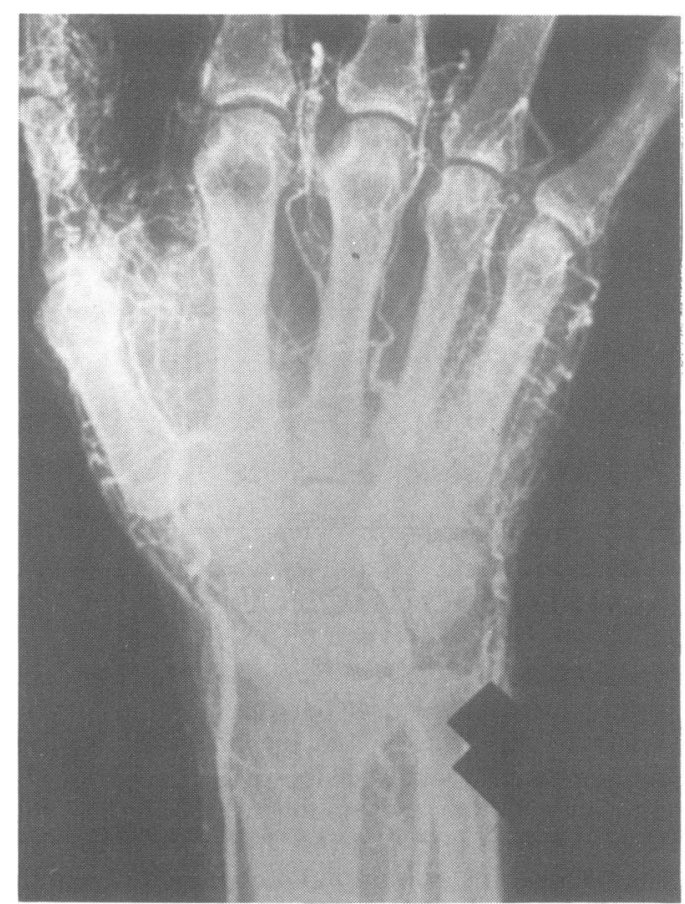

Although an aneurysm has formed the palmar arch remains patent. Digital ischaemia presumably results from embolism to digital vessels.

blueness of his right little finger. These symptoms were initially treated by his general practitioner with a vasodilator resulting in a partial improvement. He was a manual worker who used his hand as a hammer and occasionally worked with power tools. He smoked 60 cigarettes a day and was not diabetic. He was taking no medication.

Routine screening investigations for arm ischaemia were all normal and once again an arch aortogram was performed. This also showed a local aneurysmal dilatation of the ulnar artery in the palm with poor filling of the digital vessels to the little and ring fingers.

After conservative treatment with simple analgesia the condition of the right little finger has spontan- 
eously improved and it is now recovered at four months follow up.

\section{Discussion}

The two cases described are examples of the hypothenar hammer syndrome but with an unusual variation in that patent palmar aneurysms were present.

The syndrome is well defined ${ }^{1-5}$ and classically occurs in the dominant hand of male, manual workers. Repeated blunt occupational trauma produces damage to the ulnar artery followed by thrombosis resulting in digital ischaemia. Typically, the hypothenar eminence is used as a hammer to strike a fixed object. It is more common than generally recognised and in one Australian study there was objective evidence of ischaemia in $14 \%$ of manual workers at risk. $^{6}$ It produces the symptoms and signs of ischaemia, often exacerbated by cold and typically affecting the ring and little fingers. In most cases the underlying pathology is one of ulnar artery occlusion and hence Allen's test which assesses the patency of the palmar arch is positive. In our patients with a patent ulnar artery aneurysm, however, Allen's test gave negative results and failed to distinguish the HHS from industrial white finger. The relatively simple technique of direct brachial angiography ${ }^{57}$ would delineate the variants of the HHS and distinguish them from industrial white finger but arteriography is not a routine practice.

This is important but not as a guide to treatment.
The HHS has a good prognosis if conservative measures, occasionally including cervical sympathectomy, are used. The differentiation matters from the standpoint of compensation since although industrial white finger is appropriate for compensation ${ }^{8}$ HHS is not.

In conclusion, HHS and industrial white finger may be clinically identical and occur in similar groups of patients. The variant we describe can only be distinguished with certainty by an angiography. Rather than advocate such an invasive investigation we would suggest that the aetiology of HHS is sufficiently well established to consider it as an industrial disease.

\section{References}

1 Ettien JJ, Allen JT, Vargas C. Hypothenar hammer syndrome. South Med J 1981;74:491-3.

2 Pinkerton JA, Helling T, Dixon D. Digital ischaemia: hypothenar hammer syndrome. Journal of the Kansas Medical Society 1975;76:125-8.

3 Little JM, Grant AF. Hypothenar hammer syndrome. Med J Aust 1972;1:49-53.

4 Pineda CJ, Weisman MH, Bookstein JJ, Saltzstein SL. Hypothenar hammer syndrome. Form of reversible Raynauds phenomenon. Am J Med 1985;79:561-70.

5 Conn J Jr, Bergan JJ, Bell JL. Hypothenar hammer syndrome: post traumatic digital ischaemia. Surgery 1970;68:1122-8.

6 Little JM, Ferguson DA. The incidence of the hypothenar hammer syndrome. Arch Surg 1972;104:684-5.

7 Benedict KT Jr, Chang W, McCready F. The hypothenar hammer syndrome. Radiology 1974;111:57-6.

8 Taylor W. Vibration white finger: a newly prescribed disease. $\mathrm{Br}$ Med J 1985;291:921-2. 